\title{
Comparative Study of Actuation Systems for Portable Upper Limb Exoskeletons
}

\author{
Soumya K Manna ${ }^{1}$, Venketesh N. Dubey ${ }^{2, *}$ \\ ${ }^{1,2}$ Faculty of Science and Technology, Bournemouth University \\ Talbot Campus, Poole, BH2 6EE, United Kingdom \\ ${ }^{1}$ smanna@bournemouth.ac.uk, 2vdubey@bournemouth.ac.uk
}

\begin{abstract}
During the last two decades, a large variety of upper limb exoskeletons have been developed. Out of these, majority are platform based systems which might be the reason for not being widely adopted for post-stroke rehabilitation. Despite the potential benefits of platform-based exoskeletons as being rugged and reliable, stroke patients prefer to have a portable and user-friendly device that they can take home. However, the types of actuator as well as the actuation mechanism used in the exoskeleton are the inhibiting factors why portable exoskeletons are mostly non-existent for patient use. This paper presents a quantitative analysis of the actuation systems available for developing portable upper arm exoskeletons with their specifications. Finally, it has been concluded from this research that there are not many stand-alone arm exoskeletons which can provide all forms of rehabilitation, therefore, a generic solution has been proposed as the rehabilitation strategy to get best out of the portable arm exoskeletons.
\end{abstract}

Keywords: Exoskeleton, Actuator, Stroke, Rehabilitation, Portable, Safety.

\section{INTRODUCTION}

Stroke is the fourth leading cause of death in the UK. At present, there are over 1.2 million stroke survivors in the UK [1]. According to the Stroke Association, the way of recovery of stroke patients depends on the process of rehabilitation which includes all orthopaedic lessons at different phases after stroke [2]. Existing manual therapy has several drawbacks such as the cost of therapy, physical issues from physiotherapy and lack of sufficient number of physiotherapists. Long-term involvement of rehabilitation therapists imposes a huge cost burden. Present annual health and social costs of caring for disabled stroke patients are estimated to be in excess of $£ 5$ billion in the UK [3]. The ratio of the number of stroke survivor to the number of experts providing rehabilitation therapy is still not satisfactory. Since the number of people suffering from stroke and different neuromuscular diseases is increasing day by day, the situation is worsening. Also, the duration of training is not adequate due to the fatigue of therapists; patients do not get repetitive and adequate rehabilitation sessions under manual intervention. It is not possible for the patients to receive the recommended amount of medical care from manual therapy [4]. It has been shown that the exoskeleton based rehabilitation can be used as an alternative [5] to regular manual therapy for improving motor function after stroke since the device can be moved in different directions to accommodate all types of exercises [6].

Many exoskeletons have been designed to provide rehabilitation service to post-stroke patients. Based on the structure, exoskeletons can be mainly divided into two categories: ground-based exoskeleton [7] and body-based exoskeleton [8]. The ground-based exoskeletons are attached to a base platform from where full arm motions are controlled. This type of exoskeleton can provide uninterrupted and intensive rehabilitation training to patients. Actuators can be placed at the human 
joint with structural support from the base [9] or remotely controlled by placing it on the backpack [10]. Most of the ground-based exoskeletons have used brushed or brushless dc motor [11] as their active actuators. Also there are some hydraulic [12], [13], [14], ,[15] and pneumatically powered exoskeletons [16], [17], [18], [19] in the market. In the ground-based exoskeleton, motion transferred to the human arm is very stable and the actuator can provide maximum torque to the joint irrespective of the weight of the arm. This type of exoskeleton requires a large space for installation. In the body based exoskeleton, all mechanical and electronic components including the power supply are placed within the exoskeleton mounted over patient's body and joints can be directly driven by actuators; same as the ground-based system or externally controlled through transmission mechanisms. If the actuator is placed at the joint, the amount of torque required to turn the joint is quite high. To achieve higher joint torque, big and heavy motors are required [20]. As a result, weight as well as size of the exoskeleton could be increased and the structure may not be wearable. Although there are new type of soft actuators like pneumatic muscle [21] or flexible fluidic actuators [22] being developed for making portable and lightweight exoskeletons, there are still a number of issues associated with these actuators that make them unsuitable for use on a multi-degree of freedom exoskeletons. The ground-based exoskeletons are suitable for rehabilitation where size and weight of the exoskeleton are not important but for a portable exoskeleton, the actuator should be small and of low weight.

Apart from the structural division of exoskeletons in terms of ground-based and body-based systems, they can also be categorized with respect to their intended applications such as exoskeleton for assistance or therapeutic device for stroke rehabilitation. There are considerable measures of differentiation between these two types of exoskeletons, the assistive exoskeleton is mainly used for providing assistive force to support in activities of daily living or to undertake strenuous tasks. On the other hand, as a therapeutic device, the type and level of external force are varied depending on the post-stroke recovery requirements; it could be assistive or resistive force based for rehabilitation. Besides the health benefits, other design properties are also considered to be significant in this survey which are comforts, ease of putting on/removing the device, purchase cost and energy consumption [23]. On this basis, a simple, user-friendly and affordable system which is lightweight and portable should be the most wanted consideration. Ground-based systems are generally expensive because all the required rehabilitation features are installed into the exoskeleton to accommodate a large variety of patients; mainly suitable for hospitals and health care centres. Such facilities are neither readily available nor affordable for an individual user. Since the ground-based exoskeletons typically use heavy and powerful actuators, the user can't avail the training facility at home or use during travel. This leads to conclude that a mechanically efficient, simple and portable arm exoskeleton is the need for patients requiring rehabilitation therapy post-stroke, so the main aim of this paper is to investigate issues related to actuators and actuation system for developing a portable upper limb exoskeleton.

Although a large number of exoskeletons have been developed and a considerable amount of research has been undertaken, there are hardly any portable upper arm exoskeletons available to the needy user. The main reason for this bottleneck is due to the choice of actuators and the supporting mechanisms for creating a portable device. There are a couple of critical factors which should be integrated into the actuation framework to develop a lightweight exoskeleton. Based on this research the key properties for selecting an actuation system is categorised into four divisions as shown in Fig. 1: the functional activities, technological characteristics, financial benefits and psychological benefits. Out of the four divisions, the first two are crucial. The functional activity defines a standard rehabilitation therapy which not only provides medical benefits but it also guarantees safety and 2 
comforts to the users. Patient's prerequisite is to have a user-friendly system which can be effortlessly put-on and taken-off, yet no standard design methodology has been documented to produce portable exoskeletons. However, some design considerations are available to make an actuated device portable. These are; the torque to weight ratio of the exoskeleton should be high enough to carry out the maximum load during exercise. The weight of the system components should be low so that the overall device is wearable and easy to move during therapy exercises. The degree of freedom (DOF) of the exoskeleton is another important factor which should be kept to a minimum to allow minimum number of actuators to be used. Efficient mechanisms should be used for transferring motion from actuator to the joint. In order to actuate the exoskeleton, the battery life is also a very important consideration for providing power to run the exoskeleton for a long time. Besides this, considerations should also be given for the cost of actuators used in the exoskeleton to make rehabilitation a cost-effective therapy compared to the manual treatment and the ease of repair and maintenance should be built into the exoskeleton. Though appearance is least important amongst all the construction parameters of the exoskeleton, it should provide a pleasant and aesthetic look to make it attractive to the patients.

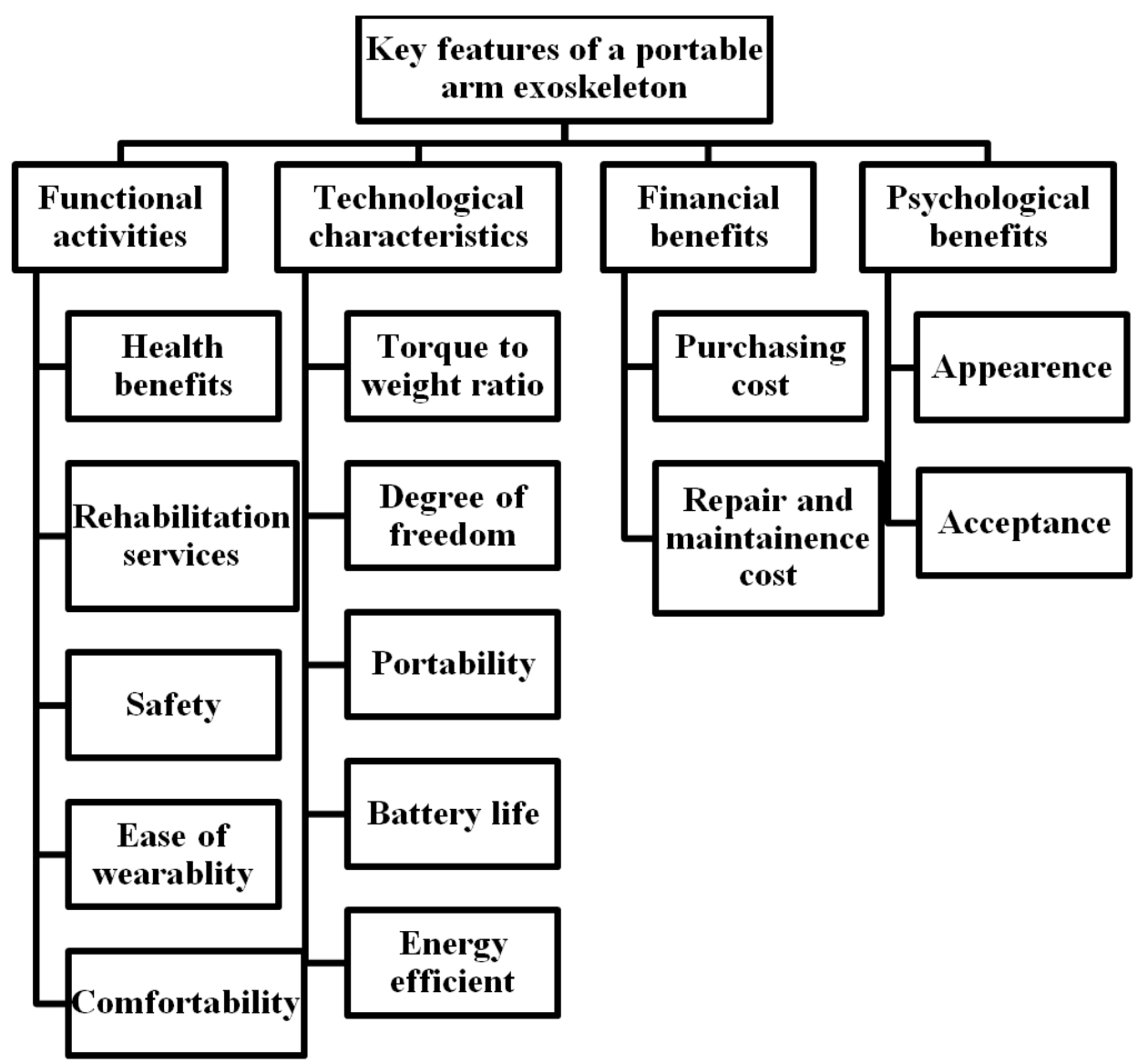

Figure 1. Key features required for a portable exoskeleton system

\section{REHABILITATION STRATEGY}

People suffering from stroke face a lot of physical and psychological problems. Physical inefficiency makes them detached from the social life. According to the standard rehabilitation strategy followed by the healthcare professionals [2], patients have to undergo different modes of exercises from acute phase to the full recovery stage after stroke. The exercises involved in different rehabilitation stages not only aimed to recover their muscle strength but also to get them back into their normal life and improve their mental strength to fit into the social life. Generally, seven standard steps are followed 
for rehabilitation as developed by the Swedish therapist Brunnstrom [24]. This approach is based on the neurophysiological principles for improving the successive levels of central nervous system (CNS) integration through a synergistic pattern of muscle movement. All these seven stages can be merged into three distinct stages after assessment of the treatment procedure involved in these stages as shown in Fig. 2. The developed exoskeleton should be capable of incorporating all types of exercises required in the three stages. Symptoms in each stage show the sign of recovery. During the acute phase, the joint movement is controlled by applying external force supported by the exoskeleton since there may be spasticity or involuntary movement in the arm. The next phase of recovery shows a better condition where a synergistic pattern in the movement appear as well as spasticity continues to decrease. During this transition, an external supportive force is helpful to implement coordination between the joint movements successfully. This phase of rehabilitation implies a partial control on the movement where patient would commence the motion from their end but assisted by the exoskeleton. The continuous synergistic motion tries to restore muscle strength and reduces the abnormality in the movement which results in a complex coordinated muscle control in the upper arm. In the full recovery stage, patients are able to initiate complex voluntary movement but not with enough strength, therefore, they need some resistance based exercises.

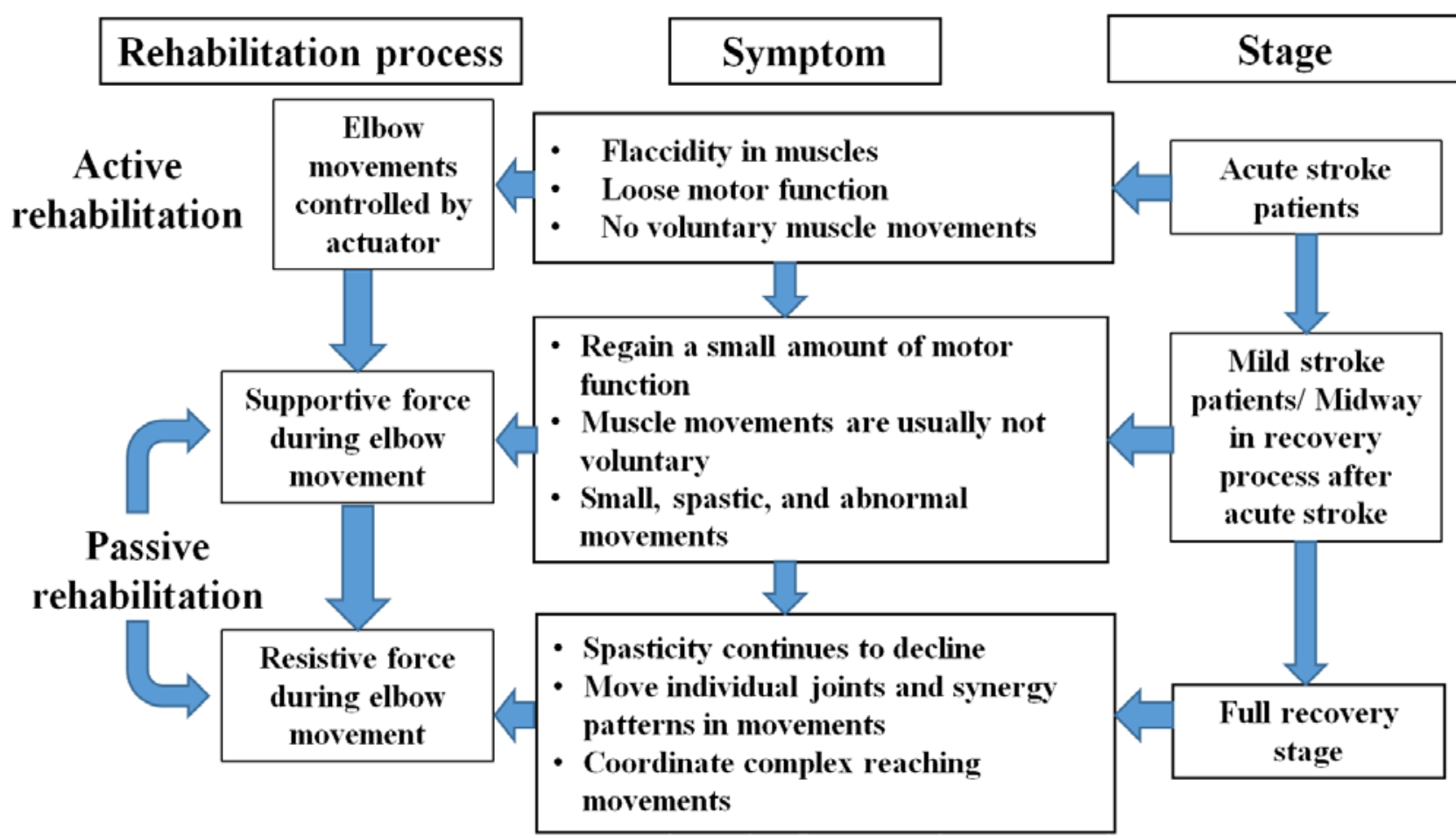

Figure 2. Three phases of the recovery process after stroke

\section{ACTUATION SYSTEM}

Since actuator and actuation mechanism used in exoskeletons are the key factors for making a portable system, different types of actuator are considered with respect to the anatomical joints of human arm. An independent actuator can provide one degree of freedom, however, some joint like shoulder has multiple degrees of freedom, therefore, the actuator selection should be based on the type of actuation required. Accordingly, actuators can be divided into three types depending on actuation used in the exoskeleton; active, semi-active and passive.

An active actuator can produce a variable range of motions with different speed and torque. Electric motor, pneumatic and hydraulic systems are the conventional active actuators which are widely used in exoskeleton design [25]. There are some new types of actuators such as artificial muscle, shape 
memory alloy (SMA), electroactive polymer (EAP), and piezoelectric motor which are also being adopted in exoskeleton designs [26]. The semi-active actuator is a special type of actuator which can't produce any active force in the joint but imposes resistive force if it has deviated from its forcebalanced position. Two types of actuation are named under this category: magnetorheological fluid based system [27] and compliant mechanisms [28]. The semi-active actuator controls the joint stiffness according to the task requirement. Passive actuators provide supporting force to the joint; it is based on passive elements like springs or rubber bands which use their elastic property to generate force without using any source of energy. After analysing the description of 46 exoskeletons [25], it was found that $56 \%$ of the exoskeletons used electric motors (either brushed or brushless) for actuation. Different actuators divided into stationary and portable systems are shown in Fig. 3. Following this survey, the passive actuation system seems to be an attractive option for making a portable device compared to exoskeletons using active actuators. From the above discussion, it should be clear that active joint movement is important for acute stage of rehabilitation which is not possible without active actuators. Out of all types of active actuators used in exoskeletons, pneumatic actuators are the competing choice for making a portable system, however, electric motors are still used in most of the stationary exoskeletons for providing active actuation due to its linear and ease of control characteristics. Fig. 4 shows a guide map of different actuators used in the existing exoskeletons.

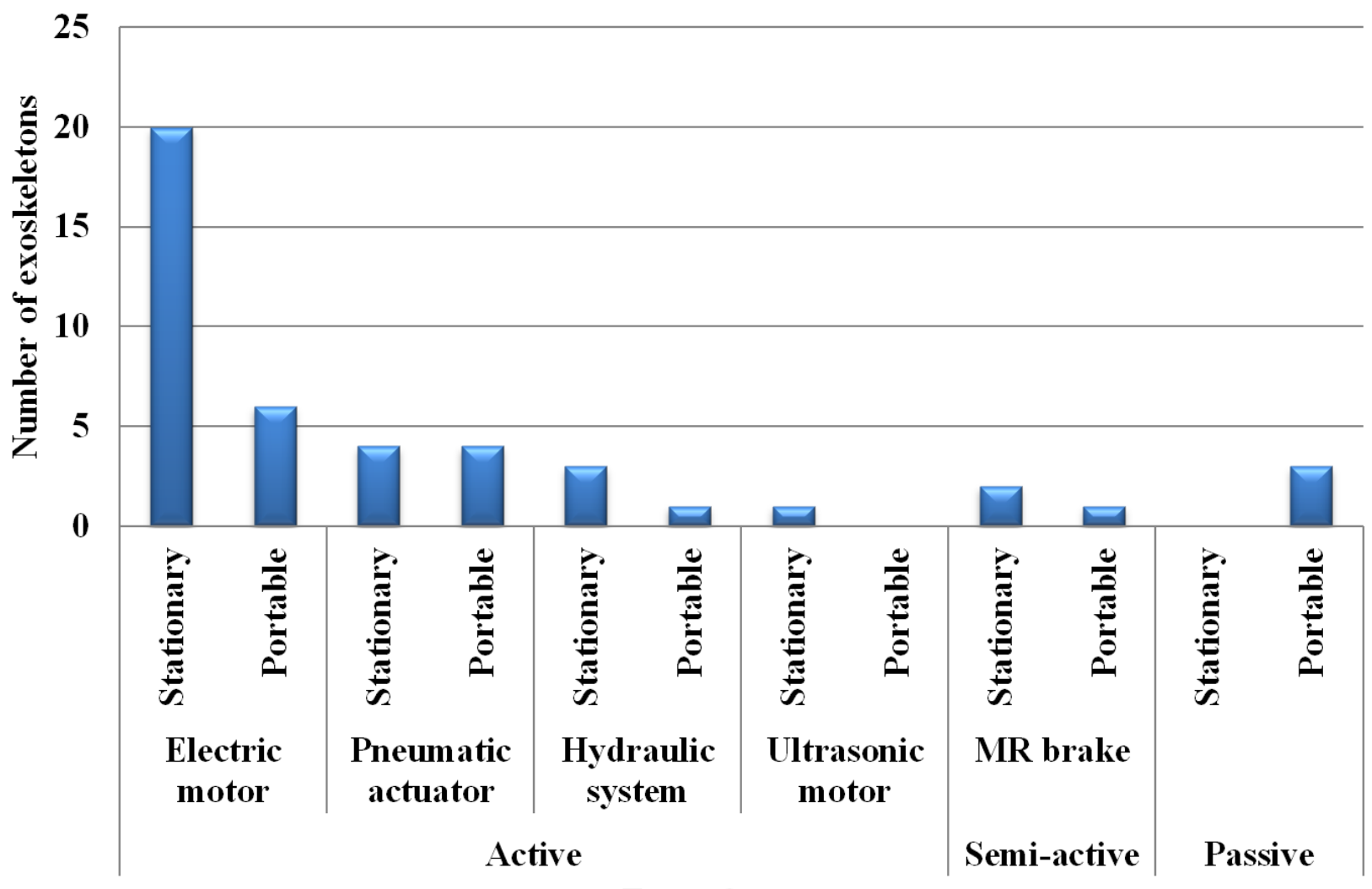

Type of actuator

Figure 3. Statistics of actuator used for stationary and portable systems 


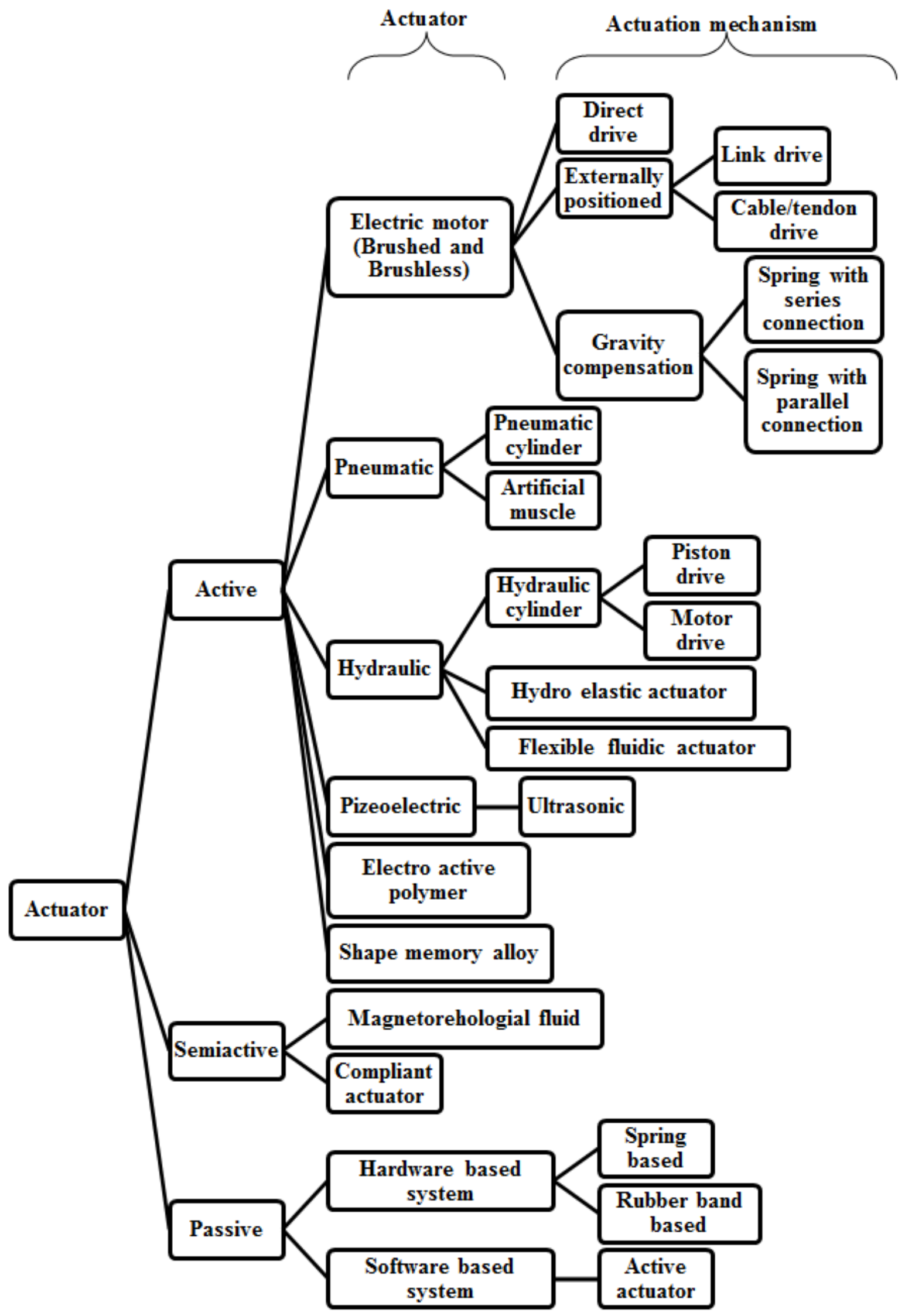

Figure 4. Actuators for stationary and portable system

\subsection{Actuators in Active rehabilitation}

At the early stage of stroke, patients undergo free movements consisting of some predefined orthopaedic lessons at different frequencies since they don't have any muscle power left. As the 
patients do not have any active participation, exercises are totally controlled by the exoskeleton as a part of active rehabilitation; motion generated by the exoskeleton is coupled to the affected limb of the patient. In the human body several muscles work together to give motion to a single joint, however, it is difficult to replicate human muscles in the exoskeleton design as large number of actuators will be required. It is possible though to achieve the same level of torque and speed using active actuators and with appropriate mechanism design. Rehabilitation training is normally performed at lower bandwidth, however, the weight and volume of the actuator may create restrictions on portability, therefore, the properties of active actuator plays an important role in providing the required torque and bandwidth for offering effective rehabilitation to patients.

\subsubsection{Electric motor}

The type of actuator used for active exoskeletons is mostly electric motor which is easy to control and has high power cum bandwidth. Generally brushed DC motor is preferred due to less cumbersome controller circuit. On the other hand, brushless motor can provide better power to weight ratio. In most of the exoskeletons, direct drive motors are used which are placed at the joint. The motor must be able to develop enough torque to start, accelerate and operate the therapy exercises at the rated speed. Exercise in active rehabilitation mode is conducted at different loads. Motors are controlled with certain characteristics to match the specific speed-torque requirements of the joint. When the exoskeleton attempts to lift the arm against gravity during rehabilitation exercise (including its own weight), it is subjected to a varying degree of torque. As these exercises are carried out by the external motor, large motors may be required to support the human arm. Problem occurs when a heavy and bulky DC motor is located at the joint which needs to be moved by the device. The condition is worse if a serial mechanical chain is attached to the arm along with motors placed at different joints. In this situation, motor placed at shoulder needs to take care of the load of the whole arm including the motor used for elbow and wrist together with the mechanical structure. Sometimes three or more motors are used in parallel for actuation since parallel manipulator behaves similar to muscle structure such as in MAHI [29]. The parallel mechanism could offer higher stiffness in a confined area but are difficult to align with the arm joints. High speed and low torque motors are smaller in size but the frequency required for rehabilitation is not more than 1-2 $\mathrm{Hz} \mathrm{[30],}$ thus such motors cannot be used. Gears are used to reduce the speed which increases the weight and reduce the efficiency typically from $70 \%$ to $50 \%$ [31]. Also, there is a problem with power consumption as it would proportionally vary with the motor torque. A portable device should have an energy source to provide uninterrupted power to the motor for a longer period. The bigger energy source adds extra weight to the exoskeleton design. To create an energy efficient mechanism, a new direction of research is required on energy optimization techniques [32].

To overcome the torque and energy-related problems, a few actuation mechanisms are developed in combination with DC motor to increase the ratio of torque/volume and torque/weight to enhance the portability. A system with low inertia can provide better dynamic performance. The most popular solution is to put the motor externally in some remote location and actuates the joint using some links or a cable driven system. Actuators can be positioned either on the backside attached to backpack [33] or on the upper arm structure [34]. The four-bar linkage mechanism is one of the best ways to transfer the motion from one point to another without any loss [35]; rigid links in mechanisms transmit forces along the link without any loss of efficiency.

In cable-driven exoskeletons, cable tension should always be maintained positive for joint actuation, however, the mechanism incurs friction loss due to cable and pulley-based system. Joint torque is also dependent on the stiffness of the cable. Cable-driven exoskeletons [34], [36], [37] and [38] have 
a large range of motion compared to other designs, however, since cable can only provide motion in one direction (only pull but not push), therefore two cables along with two actuators are required to create a bi-directional motion for a joint.

Wherever motor is used in combination with a speed reducing or torque enhancing mechanism, it affects its dynamic range. If a provision is made to offload the actuator torque by compensating the gravity, it not only improves the power requirement of the system but it also helps in making it portable. This is called passive gravity compensation technique. The passive gravity compensation can be achieved by adding a mechanical spring to the actuator where the spring energy is used to compensate a portion of the torque requirement of the motor [39]. A new compensating model has been developed by integrating an elastic element like spring in combination with actuator. This is called series elastic actuator which not only decreases the impendence but also provides stabilizing force in gravity compensation [40]. This configuration introduces more resonances in the system but lowers the functional bandwidth [31]. As arm rehabilitation doesn't require higher bandwidth, this configuration has been used in many exoskeletons [40], [41]. The elastic element also ensures safety [42] of patient during arm movement by providing compliance to the system which is one of the main criteria for designing such an exoskeleton with elastic actuators.

The harmonic drive can produce high gear ratio and high torque in a compact space [43]. It can also execute complex dynamic behaviour than conventional gear transmission. HAL is a harmonic drive based commercial full-body exoskeleton [44]. Connecting a spring in series with actuator using cable driven system [40] has less functionality compared to the directly actuated joint but the spring energy helps to reduce the joint torque requirement. The tension of the spring can be adjusted by the motor connected to it so that it can support some extra load of the arm (or exercise with a different load in hand). To avoid frictional loss and backlash, DC motor has been used with a cable-capstan reducer [45] in place of the conventional speed reducer. A motor connected to capstan adjusts the tension between spring and joint, by using the planetary gearbox with limited backlash and low reduction ratio, the frictional loss as well as a creep in the cable-driven system can be reduced. Sometimes a slip clutch is attached to DC motor to provide safety from spastic motions [46], it acts as a torquelimiting device. If the joint torque exceeds a certain limit, the slip clutch will dissociate the actuator from the exoskeleton frame and it allows free movement to the affected arm if spasm occurs in the human joint. Clutches can also be utilized for enhancing the functionality of springs or actuators in exoskeletons [47].

\subsubsection{Hydraulic actuator}

The hydraulically actuated joint can produce the highest torque to weight ratio [48] but not suitable for a portable device since the whole system needs a pump along with a reservoir to provide compressive oil for generation of motion. Compressive fluid is injected into the hydraulic cylinder under high pressure to produce push and pull force. This has the problems of oil leakage and control is non-linear. Exoskeleton like NEUROEXOS [12] has a big cylinder and pump connected to it, therefore, it is very difficult to relocate these components during motion. However, the leadscrew based motor driven system has also been used in combination with a hydraulic cylinder to provide bi-directional motion. There are some other types of the hydraulic actuators which have been designed to enhance portability such as the hydro-elastic actuator (HEA) [49] and the flexible fluidic actuator (FFA) [22]. Hydro-elastic actuator creates rotational force using a motor in combination with a spring which maintains the elasticity during motion. But it has the disadvantage of using a separate motor for a single joint movement whereas a single reservoir with a pump is enough to give power to all hydraulic cylinders in an exoskeleton. FFA is a modular fluidic actuator which has been 
applied for elbow joint. FFA consists of reinforced flexible bellows that expand during pressurization. If an FFA is connected between two links, it gives rotational motion to the joint. It also uses a small hydraulic pump and a small portable reservoir for its own operation to make it a lightweight portable device.

\subsubsection{Pneumatic actuator}

Pneumatic actuators also have a good power to weight ratio. Two types of pneumatic actuator have been developed so far; pneumatic cylinder and artificial muscle. Pneumatic cylinder acts like a hydraulic cylinder where compressed air is used instead of oil to give compliant motion in both directions. The artificial muscle, also known as Mckibben muscle [21], contracts like natural muscles and the main advantage is that it offers higher torque to weight ratio compared to the existing active actuators. Its impedance is also lower compared to electric motors. Exoskeletons like RUPERT [18], Pneu-Wrex [17], ASSIST [50], Salford arm [51] fall under this category. Artificial muscle has two layers made up of braided nylon, when it is pressurized with compressed $\mathrm{CO}_{2}$, the braided material expands and the axial length contracts, thus exhibiting similar behaviour like human muscle. This type of actuator addresses the issue of smoothness, lightness and compliance. Therefore exoskeletons actuated by pneumatic muscle are also called soft-robots. It produces natural compliance in the structure which makes the exoskeleton more ergonomic and user-friendly. Exo-suit [52] is one of the best examples of soft-robot developed at Harvard University where the soft fabric is used as the structural material and small wearable sensors are used for measuring the human movement. This type of exoskeleton can be fitted and folded under the clothes enabling the user to keep away from any public glare. Researchers have modelled different fabric with the thermal adhesive film placed in the pneumatic muscle [53] to improve the performance of the exoskeleton. A few hand-based soft robotic exoskeletons (installed with pneumatic actuators) [54], [55] are also developed for hand assistance and rehabilitation applications. However, artificial muscle has a series of problems like low bandwidth, non-linear characteristics, unidirectional operation and bigger size. Because of its bigger size, it is difficult to place in a small area with other components. Since it operates in one direction, a pair of pneumatic muscle is required for achieving bi-directional joint motion. Human joint having several degrees of freedom such as shoulder joint and wrist are difficult to make using this actuator.

\subsubsection{Electroactive polymer}

Electroactive polymer (EAP) is a newly developed elastic material that has many similarities to human muscles [56]. In this material, actuation is generated because of ionic species movement that can be used for micromanipulation in the exoskeleton. It offers several advantages such as high bandwidth and higher levels of electrical-to-mechanical power conversion ratio but has very low torque to weight ratio. For this reason, at present, it is not fit for exoskeleton actuation. But further research on EAP can enhance its properties to make it suitable for portable exoskeleton design.

\subsubsection{Ultrasonic motor}

The ultrasonic actuator could be the solution for portable exoskeletons in terms of high power to weight ratio [57]. It creates mechanical vibration based on the piezoelectric effect. The ultrasonic motor consists of two parts; stator converts the electrical energy into mechanical vibration and the rotor transforms the vibration into rotational motion using friction. Two piezoelectric elements are connected together in series and used to transfer the vibration from stator to rotor. The advantage of using ultrasonic motor is that the ratio of torque/weight and torque/volume are 20 times larger 
compared to DC motors [26]. It is lightweight and compact size actuator and doesn't create any electromechanical noise during operation. It can also work at a low speed which is very much desirable for rehabilitation. However, it requires local force feedback to control its function. These actuators are very stiff and difficult to manufacture because of high production cost [58].

\subsubsection{Shape memory alloy}

The shape memory alloy (SMA) also behaves more or less like EAP and artificial pneumatic muscle. It can be an alternative to an application which requires less movement. It is categorised as smart material made up of different metal alloy specially copper-aluminium-nickel and nickel-titanium but can also be created from alloying-zinc, copper, gold, and iron. Heating causes deformation in the metal and it returns to its initial stage after cooling. It acts like a memory strip by retrieving its predeformed shape before heating. The movement in SMA appears due to the shifting of crystalline structure between two stages, known as martensite and austenite. The low-temperature phase is called martensite and high-temperature phase is called austenite. One of its special characteristics is high power to weight ratio which makes it suitable for actuator applications. The high nonlinearity including hysteresis makes controlling of the SMA actuator troublesome [59]. Additionally, the bandwidth of SMA is quite low because of the cooling cycle. Mostly, hand exoskeletons have been developed using SMA. For example, a hand orthosis [60] was developed for quadriplegic patients where the flexion motion is supported by SMA or a differential rotational actuator [61] was used based on shape memory alloy to drive an exoskeleton for hand rehabilitation. A few exoskeletons have been developed with shape memory alloy wire-based actuators for elbow joint [62] and forearm cum wrist [63] for rehabilitation of post-stroke patients.

Table 1 shows technical specifications of some existing exoskeletons with their actuator and actuation system.

\begin{tabular}{|c|c|c|c|c|c|c|c|}
\hline Exoskeleton Design & Actuator & $\begin{array}{c}\text { Actuation } \\
\text { system }\end{array}$ & $\begin{array}{c}\text { Degree of } \\
\text { freedom }\end{array}$ & Attached to & Weight & Torque & Portability \\
\hline Arm-in [9] & $\begin{array}{l}\text { Harmonic } \\
\text { Drive }\end{array}$ & $\begin{array}{c}\text { Direct drive \& } \\
\text { link drive }\end{array}$ & 6 & $\begin{array}{l}\text { Shoulder, elbow, } \\
\text { forearm wrist }\end{array}$ & $18.76 \mathrm{~kg}$ & $\begin{array}{c}37.76 \\
\mathrm{Nm}\end{array}$ & No \\
\hline $\begin{array}{c}\text { MGA exoskeleton } \\
{[64]}\end{array}$ & $\begin{array}{c}\text { Electric } \\
\text { motor }\end{array}$ & Direct drive & 7 & $\begin{array}{c}\text { Shoulder, elbow, } \\
\text { and forearm }\end{array}$ & $12 \mathrm{~kg}$ & $137 \mathrm{Nm}$ & No \\
\hline ExoRob [65] & $\begin{array}{l}\text { Harmonic } \\
\text { Drive }\end{array}$ & Direct drive & 5 & $\begin{array}{l}\text { Elbow joint and } \\
\text { wrist joint }\end{array}$ & $\begin{array}{l}\text { Actuator } \\
\text { weight- } \\
1.15 \mathrm{~kg}\end{array}$ & $5.5 \mathrm{Nm}$ & No \\
\hline $\begin{array}{c}\text { MEDARM } \\
\text { [36] }\end{array}$ & $\begin{array}{c}\text { Electric } \\
\text { motor }\end{array}$ & Cable drive & 3 & $\begin{array}{c}\text { Shoulder, elbow, } \\
\text { wrist }\end{array}$ & $115 \mathrm{~kg}$ & $73 \mathrm{Nm}$ & No \\
\hline $\begin{array}{c}\text { ShouldeRO } \\
\text { [37] }\end{array}$ & $\begin{array}{c}\text { Linear } \\
\text { actuator }\end{array}$ & $\begin{array}{c}\text { Bowden } \\
\text { Cables }\end{array}$ & 2 & Shoulder joint & $1 \mathrm{~kg}$ & $50 \mathrm{Nm}$ & No \\
\hline NEUROEXOS [12] & $\begin{array}{l}\text { Hydraulic } \\
\text { drive }\end{array}$ & $\begin{array}{c}\text { Antagonistic } \\
\text { Compliant } \\
\text { actuation }\end{array}$ & 3 & Shoulder joint & $\begin{array}{l}2.30 \mathrm{~kg} \\
\text { (without the } \\
\text { weight of } \\
\text { pump and } \\
\text { reservoir) }\end{array}$ & $15 \mathrm{Nm}$ & No \\
\hline $\begin{array}{c}\text { Multiple Joint } \\
\text { Robotic Arms [66] }\end{array}$ & $\begin{array}{c}\text { Ultrasonic } \\
\text { motor }\end{array}$ & Direct drive & 4 & $\begin{array}{c}\text { Shoulder, elbow, } \\
\text { wrist }\end{array}$ & - & $63 \mathrm{Nm}$ & No \\
\hline Skeleton Arm [67] & $\begin{array}{c}\text { Electric } \\
\text { motor }\end{array}$ & $\begin{array}{l}\text { Tendon- } \\
\text { driven }\end{array}$ & 6 & Human arm & - & - & No \\
\hline BONES [16] & Pneumatic & $\begin{array}{c}\text { Parallel } \\
\text { drive }\end{array}$ & 4 & $\begin{array}{c}\text { Shoulder and } \\
\text { elbow }\end{array}$ & - & $22 \mathrm{Nm}$ & No \\
\hline Dampace [13] & $\begin{array}{c}\text { Hydraulic } \\
\text { actuator }\end{array}$ & $\begin{array}{c}\text { Cable \& } \\
\text { spring drive }\end{array}$ & 4 & $\begin{array}{c}\text { Shoulder and } \\
\text { elbow }\end{array}$ & - & $50 \mathrm{Nm}$ & No \\
\hline Limpact [49] & $\begin{array}{c}\text { Rotational } \\
\text { hydroelectric } \\
\text { actuator }\end{array}$ & $\begin{array}{c}\text { Direct } \\
\text { drive, cable \& } \\
\text { spring drive }\end{array}$ & 4 & $\begin{array}{l}\text { Shoulder and } \\
\text { elbow }\end{array}$ & $8 \mathrm{~kg}$ & $36 \mathrm{Nm}$ & No \\
\hline Pneu-Wrex & Pneumatic & Link drive & 4 & Shoulder, elbow, & - & $80 \mathrm{~N}$ & No \\
\hline
\end{tabular}

Table 1.Exoskeleton with active actuator 


\begin{tabular}{|c|c|c|c|c|c|c|c|}
\hline$[17]$ & & & & and finger joint & & force & \\
\hline Intelliarm [68] & Electric motor & $\begin{array}{l}\text { Direct drive \& } \\
\text { cable drive }\end{array}$ & 9 & $\begin{array}{l}\text { Shoulder, elbow, } \\
\text { wrist and finger } \\
\text { joint }\end{array}$ & - & $\begin{array}{c}10.20 \\
\mathrm{Nm}\end{array}$ & No \\
\hline SUEFUL-7 [69] & $\begin{array}{l}\text { DC servo } \\
\text { motor }\end{array}$ & $\begin{array}{l}\text { Direct drive \& } \\
\text { gear drive }\end{array}$ & 7 & $\begin{array}{l}\text { Shoulder, elbow, } \\
\text { wrist and finger } \\
\text { joint }\end{array}$ & $5 \mathrm{~kg}$ & $5.90 \mathrm{Nm}$ & No \\
\hline $\begin{array}{c}\text { MIME-RiceWrist } \\
\text { [29] }\end{array}$ & $\begin{array}{c}\text { Electric } \\
\text { motor }\end{array}$ & $\begin{array}{c}\text { Parallel } \\
\text { drive }\end{array}$ & 3 & Wrist & $1.96 \mathrm{~kg}$ & $5.08 \mathrm{Nm}$ & No \\
\hline $\begin{array}{c}\text { Salford } \\
\text { Rehabilitation } \\
\text { exoskeleton } \\
{[51]}\end{array}$ & $\begin{array}{l}\text { Pneumatic } \\
\text { muscle }\end{array}$ & $\begin{array}{l}\text { Antagonistic } \\
\text { actuation }\end{array}$ & 7 & $\begin{array}{l}\text { Shoulder, elbow, } \\
\text { and wrist }\end{array}$ & $2 \mathrm{~kg}$ & $30 \mathrm{Nm}$ & No \\
\hline $\begin{array}{c}\text { CADEN-7 } \\
\text { [38] }\end{array}$ & $\begin{array}{l}\text { DC Brushed } \\
\text { motor }\end{array}$ & Cable drive & 14 & $\begin{array}{c}\text { Shoulder, elbow, } \\
\text { forearm and } \\
\text { wrist }\end{array}$ & $6.80 \mathrm{~kg}$ & $6.20 \mathrm{Nm}$ & No \\
\hline WOTAS [70] & DC motor & Direct drive & 3 & $\begin{array}{c}\text { Elbow, forearm, } \\
\text { wrist }\end{array}$ & $0.85 \mathrm{~kg}$ & $8 \mathrm{Nm}$ & Yes \\
\hline MAHI Exos-II [71] & $\begin{array}{l}\text { Frameless } \\
\text { DC } \\
\text { brushless } \\
\text { motor }\end{array}$ & $\begin{array}{l}\text { Parallel } \\
\text { drive }\end{array}$ & 5 & $\begin{array}{l}\text { Elbow, forearm, } \\
\text { wrist }\end{array}$ & $\begin{array}{l}3 \text { motors with } \\
\text { arms } \\
\text { assembly. } \\
\text { Motor weight } \\
-0.48 \mathrm{~kg} \\
\end{array}$ & $\begin{array}{c}11.61 \\
\mathrm{Nm}\end{array}$ & Yes \\
\hline $\begin{array}{c}\text { RehabExos } \\
\text { [72] }\end{array}$ & $\begin{array}{l}\text { Frameless } \\
\text { DC } \\
\text { brushless } \\
\text { motor }\end{array}$ & Direct drive & 4 & $\begin{array}{l}\text { Shoulder, elbow, } \\
\text { and forearm }\end{array}$ & $\begin{array}{l}\text { Motor weight } \\
3.70 \mathrm{~kg}\end{array}$ & $150 \mathrm{Nm}$ & No \\
\hline ARAMIS [73] & $\begin{array}{l}\text { DC brushed } \\
\text { motor }\end{array}$ & Direct drive & 12 & $\begin{array}{l}\text { Shoulder, elbow, } \\
\text { and forearm }\end{array}$ & $19 \mathrm{~kg}$ & $94 \mathrm{Nm}$ & No \\
\hline iPAM [19] & Pneumatic & Link drive & 6 & $\begin{array}{c}\text { Shoulder, elbow, } \\
\text { and forearm }\end{array}$ & $\begin{array}{l}\text { Wheelchair- } \\
\text { based system }\end{array}$ & $15 \mathrm{Nm}$ & No \\
\hline L-Exos [74] & $\begin{array}{l}\text { Electric } \\
\text { motor }\end{array}$ & $\begin{array}{l}\text { Cable and } \\
\text { link drive }\end{array}$ & 5 & $\begin{array}{l}\text { Shoulder, elbow, } \\
\text { and forearm }\end{array}$ & $11 \mathrm{~kg}$ & $\begin{array}{c}\text { Motor } \\
\text { torque- } \\
3.70 \mathrm{Nm}\end{array}$ & No \\
\hline MULOS [75] & $\begin{array}{c}\text { Electric } \\
\text { motor }\end{array}$ & Direct drive & 5 & $\begin{array}{c}\text { Shoulder, elbow, } \\
\text { and forearm }\end{array}$ & $\begin{array}{l}\text { Wheelchair- } \\
\text { based system }\end{array}$ & $\begin{array}{c}14.95 \\
\mathrm{Nm}\end{array}$ & No \\
\hline $\begin{array}{c}\text { Hybrid Elbow } \\
\text { Orthosis [15] }\end{array}$ & Hydraulic & $\begin{array}{l}\text { Flexible } \\
\text { fluidic } \\
\text { actuation } \\
\text { using } \\
\text { bellows } \\
\end{array}$ & 1 & elbow & $1.20 \mathrm{~kg}$ & $3 \mathrm{Nm}$ & Yes \\
\hline Exorn [76] & $\begin{array}{c}\text { DC Brushed } \\
\text { and } \\
\text { brushless } \\
\text { motor }\end{array}$ & Direct drive & 10 & $\begin{array}{l}\text { Shoulder, elbow, } \\
\text { forearm and } \\
\text { wrist }\end{array}$ & $10 \mathrm{~kg}$ & $\begin{array}{l}\text { Motor } \\
\text { torque- } \\
30 \mathrm{Nm}\end{array}$ & Yes \\
\hline ALEx [77] & $\begin{array}{l}\text { Brushless } \\
\text { motor }\end{array}$ & Direct drive & 6 & $\begin{array}{c}\text { Shoulder, elbow, } \\
\text { forearm and } \\
\text { wrist }\end{array}$ & $14.50 \mathrm{~kg}$ & $80 \mathrm{Nm}$ & Yes \\
\hline ABLE [78] & $\begin{array}{c}\text { Electric } \\
\text { motor }\end{array}$ & Link drive & 4 & $\begin{array}{c}\text { Shoulder, elbow, } \\
\text { and wrist }\end{array}$ & - & $18 \mathrm{Nm}$ & No \\
\hline SAM [45] & $\begin{array}{l}\text { Electric } \\
\text { motor }\end{array}$ & $\begin{array}{c}\text { Capstone } \\
\text { wheel based } \\
\text { direct } \\
\text { drive } \\
\end{array}$ & 7 & $\begin{array}{c}\text { Shoulder, elbow, } \\
\text { forearm and } \\
\text { wrist }\end{array}$ & $6 \mathrm{~kg}$ & $\begin{array}{l}19.70 \\
\mathrm{Nm}\end{array}$ & No \\
\hline Myomo [79] & DC motor & Direct drive & 4 & Elbow and wrist & - & - & Yes \\
\hline SUE [80] & Pneumatic & Link drive & 2 & $\begin{array}{c}\text { Forearm and } \\
\text { wrist }\end{array}$ & $0.56 \mathrm{~kg}$ & - & Yes \\
\hline $\begin{array}{c}\text { Self-aligning } \\
\text { exoskeleton [81] }\end{array}$ & $\begin{array}{l}\text { Electric } \\
\text { motor }\end{array}$ & $\begin{array}{c}\text { Gear drive } \\
\text { and direct } \\
\text { drive }\end{array}$ & 3 & $\begin{array}{l}\text { Forearm and } \\
\text { wrist }\end{array}$ & - & $3 \mathrm{Nm}$ & Yes \\
\hline Exo-suit [52] & $\begin{array}{l}\text { Soft textile } \\
\text { pneumatic } \\
\text { actuator } \\
\end{array}$ & Direct drive & 1 & Shoulder & - & $20 \mathrm{Nm}$ & Yes \\
\hline $\begin{array}{l}\text { Pneumatic elbow } \\
\text { exoskeleton [53] }\end{array}$ & $\begin{array}{c}\text { Pneumatic } \\
\text { muscle }\end{array}$ & Direct drive & 1 & Elbow & $0.30 \mathrm{~kg}$ & $\begin{array}{l}300 \mathrm{~N} \\
\text { force }\end{array}$ & Yes \\
\hline ExoGlove [54] & $\begin{array}{c}\text { Soft } \\
\text { pneumatic }\end{array}$ & Direct drive & - & Hand & $0.20 \mathrm{~kg}$ & - & Yes \\
\hline
\end{tabular}




\begin{tabular}{|c|c|c|c|c|c|c|c|}
\hline & actuator & & & & & & \\
\hline $\begin{array}{c}\text { Hand rehabilitation } \\
\text { system [61] }\end{array}$ & $\begin{array}{c}\text { Shape } \\
\text { memory alloy }\end{array}$ & Direct drive & 3 & Finger & - & $\begin{array}{l}20 \mathrm{~N} \\
\text { force }\end{array}$ & Yes \\
\hline $\begin{array}{c}\text { Soft Robotics } \\
\text { Wearable Elbow } \\
\text { Exoskeleton [62] }\end{array}$ & $\begin{array}{c}\text { Shape } \\
\text { memory alloy }\end{array}$ & $\begin{array}{l}\text { Bowden } \\
\text { Cables }\end{array}$ & 1 & Elbow & $0.60 \mathrm{~kg}$ & $\begin{array}{c}\text { Pulling } \\
\text { force- } \\
34.9 \mathrm{~N}\end{array}$ & Yes \\
\hline $\begin{array}{c}\text { Wearable Wrist and } \\
\text { Forearm } \\
\text { Exoskeleton [63] }\end{array}$ & $\begin{array}{c}\text { Shape } \\
\text { memory alloy }\end{array}$ & $\begin{array}{l}\text { Spring and } \\
\text { cable drive }\end{array}$ & 3 & Elbow and wrist & $0.95 \mathrm{~kg}$ & $20 \mathrm{Nm}$ & Yes \\
\hline
\end{tabular}

\subsection{Methods in passive rehabilitation}

Patients are able to initiate joint movements after rigorous active rehabilitation after which they recover some muscle strength. However, they can hardly balance their arms in a particular position as well as to keep it in a certain configuration for a long time. Therefore, an assistive force would be helpful to patients to continue their movements for different exercises. The supportive force would encourage the patients to engage in more efforts during exercises. As a result, their neuro-motor function will improve gradually. Passive rehabilitation can be achieved using either an active actuator or passive elements.

\subsubsection{Software based solution}

The idea of passive exoskeleton is to provide supportive force to patients to generate easy voluntary movements. The first solution for this is based on soft computing approach [65] where the control algorithm can measure the patient's intention of movement using different biosensors (EMG ${ }^{1}$ and $\mathrm{EEG}^{2}$ ). Therefore, an adaptive control system can generate variable motor torque based on the patient's effort taken from the sensory data. If it is found that patients are unable to do the exercise on their own, the control system adjusts the required motor torque which would assist them to improve their arm movement. The generated joint torque will be reduced in case of improved health status, but there are some limitations regarding the stability of feedback signals. In software based solution, the exoskeleton may exhibit a discordant behaviour on sudden impact force due to the delay in signal transmission. Continuous engagement of electric motor along with other electronic components results in constant draining of energy. This approach may not suitable for an energy efficient mechanism. Also, the human joint motion is always under motor control which might not be safe, if the motor moves beyond the anatomical limit of human joint due to malfunction, accident might happen.

\subsubsection{Hardware based solution}

In hardware-based approach, opposite forces are generated against the gravity to achieve a particular movement. A solution of putting a counterweight on the opposite side of the load can balance the arm under gravity [82]. But this is not a desirable solution for a portable system where weight reduction is the main objective. A passive elastic element such as spring or rubber band can support the arm by reducing the gravity force for arm movement. Spring always tries to get into its original shape and because of its stiffness, it can create an opposite force to gravity resulting in a bare minimum force required for joint actuation. In fact, passive elastic based mechanism creates energyfree system because no active actuator is involved in the motion.

Springs connected to the supporting mechanism are made up of solid links [83]. Front-end or rearend position of the spring are connected to two separate links which are coupled with two different

${ }^{1}$ EMG - Electromyography

${ }^{2}$ EEG - Electroencephalography 
parts of the body. The joint movement causes extension of the spring resulting in an opposite restoring force about the joint. It helps the exoskeleton to take care of the arm load if it is going against the gravity. Assistive force can be varied by changing the connection points of the spring in the mechanism. However, in spring supported systems, the range of motion is less due to its own free length. Spring length restricts the motion to a certain extent but the complex link mechanism may increase the efficiency of joint in terms of torque and the range of motion. Full range of motion can be achieved using zero-free-length springs which are quite difficult to manufacture. To increase the range of motion, sometimes cable is attached with the spring [84]. One solution is to place it in a remote location and transfer the spring force using cables. Use of rubber band is also an option of providing assistive force in passive rehabilitation. T-WREX [85] is a commercial passive exoskeleton based on rubber bands, it is a simple and component wise less expensive device.

Sometimes torque requirement for joint movement is different for different users depending on size and weight of their arm. Also, a user needs variable torque for lifting different loads during exercise; there are two ways to change the spring force dynamically during operation. One is to vary the number of active coils in the spring [86] and the other is to change the front-end or rear-end position of the spring [87]. The first solution would change the stiffness of the particular spring while the second solution would change the spring force by varying the amount of displacement. However, it is necessary to ensure that the changing of spring force should not be permanent and it should be able to return to its initial position. Most of the variable gravity compensation mechanisms have used an extra motor to change the spring force. This form of solution may be suited from a control point of view but not for a portable device because the extra motor increases the weight as well as the size of the system. Lists of a few passive exoskeletons (with no active actuator) are shown in Table. 2.

Table 2.Exoskeleton with passive element (spring \& rubber band)

\begin{tabular}{|c|c|c|c|c|c|c|c|}
\hline $\begin{array}{c}\text { Exoskeleton } \\
\text { Design }\end{array}$ & $\begin{array}{c}\text { Actuating } \\
\text { system }\end{array}$ & $\begin{array}{c}\text { Passive } \\
\text { elements }\end{array}$ & $\begin{array}{c}\text { Degree of } \\
\text { freedom }\end{array}$ & Attached to & Weight & Torque & Portability \\
\hline T-WREX [85] & Link drive & Rubber band & 5 & $\begin{array}{c}\text { Shoulder, elbow, and } \\
\text { finger }\end{array}$ & - & $\begin{array}{c}\text { Wheelchair-based } \\
\text { system }\end{array}$ \\
\hline Armon [84] & $\begin{array}{c}\text { Link drive } \\
\text { and cable } \\
\text { drive }\end{array}$ & Spring based & 3 & $\begin{array}{c}\text { Shoulder, elbow, and } \\
\text { wrist }\end{array}$ & $\begin{array}{c}\text { 23 N } \\
\text { force }\end{array}$ & $\begin{array}{c}\text { Wheelchair-based } \\
\text { system }\end{array}$ \\
\hline SLERT [83] & Link drive & Spring based & 4 & Shoulder, elbow & - & - & No \\
\hline Armeospring [88] & Link drive & Spring based & 7 & $\begin{array}{c}\text { Shoulder, elbow, } \\
\text { wrist and finger } \\
\text { joint }\end{array}$ & - & - & No \\
\hline $\begin{array}{c}\text { Hybrid arm } \\
\text { support [89] }\end{array}$ & Link drive & Spring based & 1 & Arm support & $10 \mathrm{~kg}$ & - & No \\
\hline
\end{tabular}

\subsection{Techniques for creating variable stiffness}

The passive rehabilitation process solely depends on patient's health condition and assistive force required. Neuromuscular activity increases in rehabilitation over time as patients gain more strength. It depends on the level of exercises undertaken by the patients during the rehabilitation training. After stroke, the training-induced cortical activation depends on the rehabilitation process and the difficulty level of the exercises which further improves progression to contralesional activation. It helps those patients to get back to the normal stage through a different learning process to make them familiar with real-time force activity. Therefore, those exercises module should be tough and strenuous from time to time so that the patients apply more efforts to complete.

Human joint stiffness is generally constant during active rehabilitation. It is not required to change the joint stiffness during active rehabilitation since no active participation is taking place from the patient whereas patient's effort is responsible for carrying out all exercises during passive rehabilitation. If the joint stiffness differs in magnitude such as to become stiffer, patient has to 
provide extra torque to move the joint. This type of training will gradually improve their neuromotor functions. There are three ways to change the joint stiffness of the mechanism.

\subsubsection{Active actuator based joint stiffness control}

Active actuator based joint stiffness control can be achieved using feedback sensor and soft computing technique to maintain the desired level of stiffness [90]. An exoskeleton can impose different joint stiffness to human arm by changing its motor torque. It is similar to the passive rehabilitation process but the difference is in the nature of force. At the start of passive rehabilitation, supporting force is generated to assist the motion whereas a resistive force is generated to restrict the joint motion later. This type of strategy is very much software dependent, therefore, change in the health status could be difficult to manage. Such neurological patients may suffer from painful and involuntary muscular contraction which may lead to a joint stiffness with undesirable joint torque.

\subsubsection{Semi-active actuator based joint stiffness control}

The semi-active actuator based stiffness control is useful for providing variable stiffness to the joint. It can't provide variable active forces to the patients but suitable for the application where resistive force is required. It uses controllable fluid where viscosity can be adjusted by changing the electromagnetic property of the fluid, thus changing the stiffness of the joint connected to it. One of the best examples is MR (Magnetorheological) brake which can provide a reaction torque up to 1.1 $\mathrm{Nm}$ [27]. The magnetorheological fluid is located between the gap of stator and rotor. It consists of micron-sized magnetic particles located inside a liquid carrier that forms a magnetic chain like structure when the external magnetic field is applied. Apparently, the viscosity of the fluid is changed, as a result the stator applies different frictional force to the rotor and the whole mechanism exerts different stiffness at the joint. The intrinsic stability provided by MR brake is of great advantage to the patient for freezing the arm at a particular location. Sometimes the semi-active actuator is used in combination with normal active actuator to provide stiffness to the joint which cannot be achieved by the semi-active actuator alone. MR brake generally works in the operating voltage of 2-25 volt with a current rating of 1-2A. Sometimes clutching using electrostatic force without tacky polymers can be enforced for changing the joint stiffness, but its effectiveness is impeded by the space charge.

\subsubsection{Compliant actuator based joint stiffness control}

Joint stiffness variation can also be accomplished by using different mechanisms. This approach reduces the complexity of control system by including different passive components in the exoskeleton structure. A few series elastic material such as spring, bending rod can be used to change the joint stiffness. However, from the mechanism point of view, there are a few established standard techniques for changing the joint stiffness but all of these techniques cannot be used for human applications. The compliant actuator is a standard solution for providing variable stiffness to the joint [91]. It provides elastic behaviour where output moves due to an external force and returns to its original state if no force is present. It uses passive elements to store and release the energy. Recent publications show that the compliant actuator is more effective as compared to those electromagnetic brakes for arm support system in terms of safety and comfort [28]. This type of actuator generates less impact force on the joint against external shocks and protects it from damage. From a technical point of view, stiffness and compliance are opposite in nature; a system consisting of a stiff actuator keeps the joint at a specific position if the external force has been removed. A compliant actuator deviates from its equilibrium position depending on the applied force; however, it 
comes back to its stable condition to have zero potential energy. Therefore, the compliant behaviour of a mechanism can justify the non-stiff behaviour of the actuator. In actual scenario, the rehabilitation process requires relatively less stiffness during exercises and the joint stiffness can be gradually raised when patient regain their muscle control.

Active compliant actuator mimics the behaviour of spring through adaptability whereas passive compliant system uses mechanical spring for providing the joint stiffness. The disadvantage in active compliance actuator is that it always consumes energy. However, to make those passive compliant systems adaptable, some additional mechanism is required to change the spring force. A few standard designs have already been developed for generating the compliant behaviour in a system. Some of these are:

- Stiffness change by antagonistic control [92]: Two non-linear springs connected with two actuators in series and coupled to a joint antagonistically, by applying force against each other and controlling the actuators equilibrium, joint position as well as stiffness can be set.

- Structure controlled stiffness: Sometimes mechanical construction like cantilever beam or bending rod behaves like a spring to provide variations in stiffness [93]. The stiffness of elastic element is determined by the material property and its dimension. Stiffness can also be controlled by adjusting the effective spring length, for example, jack spring [86] uses a mechanism to control the effective number of active coils to vary the stiffness.

Most of the designs with variable stiffness mechanism generally use spring-based control system which is operated by one or two active motors. However, the engagement of extra motor or mechanism increases the overall weight which is one of the main inhibiting factors of portable exoskeleton device development.

Actuators with the back-drivable facility are also used for providing safety and comfort. Stiff actuator requires higher amount of torque to turn a joint whereas back-drivable actuator can turn the joint with a small amount of torque thus adding compliance to the joint. If the back-drivability is too low, the gearbox can be damaged due to sudden external force. Mechanical systems experience more resonances [31] and the reduction of system bandwidth happens due to the addition of springs. A few exoskeletons offering variable stiffness to arm joint are shown in Table.3.

\begin{tabular}{|c|c|c|c|c|c|c|c|}
\hline Exoskeleton Design & Actuating system & Actuator & $\begin{array}{l}\text { Degree of } \\
\text { freedom }\end{array}$ & $\begin{array}{c}\text { Attached } \\
\text { to }\end{array}$ & Weight & Torque & Portability \\
\hline \multicolumn{8}{|c|}{ Semi-active actuator } \\
\hline MEM-MRB [27] & Link drive & $\begin{array}{l}\text { Magneto-rheological } \\
\text { fluid brake }\end{array}$ & 1 & Elbow & $\begin{array}{c}26.40 \\
\mathrm{~kg}\end{array}$ & $27.5 \mathrm{Nm}$ & No \\
\hline MUNDUS [94] & $\begin{array}{l}\text { Link and } \\
\text { cable drive }\end{array}$ & $\begin{array}{c}\text { Electromagnetic DC } \\
\text { brake }\end{array}$ & 3 & $\begin{array}{l}\text { Shoulder, } \\
\text { and elbow }\end{array}$ & $2.20 \mathrm{~kg}$ & - & $\begin{array}{c}\text { Wheelchair- } \\
\text { based } \\
\text { system }\end{array}$ \\
\hline DVB orthosis [95] & Link drive & $\begin{array}{l}\text { Magneto-Rheological } \\
\text { Fluid }\end{array}$ & 1 & Wrist & $\begin{array}{c}<0.20 \\
\mathrm{~kg}\end{array}$ & $\begin{array}{l}50 \mathrm{~N} \\
\text { peak } \\
\text { force }\end{array}$ & Yes \\
\hline \multicolumn{8}{|c|}{ Complaint actuation system } \\
\hline $\begin{array}{c}\text { Biologically } \\
\text { Inspired Joint [92] }\end{array}$ & $\begin{array}{c}\text { Antagonistic series } \\
\text { elastic } \\
\text { actuation }\end{array}$ & Electric motor & 1 & Any joint & - & - & - \\
\hline VSA-II [96] & $\begin{array}{c}\text { Antagonistic series } \\
\text { elastic } \\
\text { actuation } \\
\end{array}$ & Electric motor & 1 & Any joint & $\begin{array}{c}0.35 \\
\mathrm{~kg}\end{array}$ & - & Yes \\
\hline AwAS-II [97] & $\begin{array}{c}\text { Lever and } \\
\text { spring based }\end{array}$ & Electric motor & 1 & Any joint & $1.10 \mathrm{~kg}$ & $80 \mathrm{Nm}$ & Yes \\
\hline $\begin{array}{c}\text { Hybrid Dual } \\
\text { Actuator Unit [98] }\end{array}$ & $\begin{array}{c}\text { Double } \\
\text { spring based }\end{array}$ & Electric motor & 1 & Any joint & $1.80 \mathrm{~kg}$ & $50 \mathrm{Nm}$ & Yes \\
\hline CompAct-VSA [99] & Lever and & Electric motor & 1 & Any joint & - & $117 \mathrm{Nm}$ & - \\
\hline
\end{tabular}




\begin{tabular}{|c|c|c|c|c|c|c|c|}
\hline & spring based & & & & & & \\
\hline vsaUT-II [100] & $\begin{array}{l}\text { Spring and belt } \\
\text { drive }\end{array}$ & Electric motor & 1 & Any joint & - & - & - \\
\hline HVSA [101] & $\begin{array}{c}\text { Lever and } \\
\text { spring based }\end{array}$ & Electric motor & 1 & Any joint & - & $8.50 \mathrm{Nm}$ & - \\
\hline VSA-CubeBot [102] & $\begin{array}{l}\text { Spring and wire } \\
\text { drive }\end{array}$ & Electric motor & 1 & Any joint & $\begin{array}{c}0.26 \\
\mathrm{~kg}\end{array}$ & $3 \mathrm{Nm}$ & Yes \\
\hline PVSA [103] & $\begin{array}{c}\text { Antagonistic } \\
\text { actuation with cam } \\
\text { drive }\end{array}$ & Electric motor & 1 & Any joint & $\begin{array}{c}0.98 \\
\mathrm{~kg}\end{array}$ & - & Yes \\
\hline VSJ [104] & Leaf-spring based & Electric motor & 1 & Any joint & $\begin{array}{c}4.95 \\
\mathrm{~kg}\end{array}$ & - & - \\
\hline DLR FSJ [105] & $\begin{array}{c}\text { Roller-based cam } \\
\text { drive }\end{array}$ & Electric motor & 1 & Any joint & $\begin{array}{c}1.41 \\
\mathrm{Kg}\end{array}$ & $67 \mathrm{Nm}$ & Yes \\
\hline mVSA-UT [106] & $\begin{array}{l}\text { Spring and gear } \\
\text { drive }\end{array}$ & Electric motor & 1 & Any joint & $\begin{array}{c}0.10 \\
\mathrm{~kg}\end{array}$ & $1 \mathrm{Nm}$ & Yes \\
\hline CCEA [107] & $\begin{array}{l}\text { Antagonistic link } \\
\text { based spring } \\
\text { drive }\end{array}$ & Electric motor & 1 & Any joint & $\begin{array}{c}0.80 \\
\mathrm{~kg}\end{array}$ & $13 \mathrm{Nm}$ & Yes \\
\hline MACCEPA [108] & $\begin{array}{c}\text { Link and } \\
\text { spring drive } \\
\end{array}$ & Electric motor & 1 & Any joint & - & - & - \\
\hline
\end{tabular}

\section{OTHER ISSUES}

Apart from the mechanism and structural framework of actuator and actuation systems used for the development of upper limb exoskeleton, there are some other issues such as the degree of freedom, bandwidth, energy consumption which are also responsible for developing portable exoskeletons.

\subsection{DEGREE OF FREEDOM (DOF)}

Driven by the bioelectric signal, the actuation force in human joint is provided by a bunch of muscle fibres which is difficult to replicate using a couple of actuators. A human arm has a minimum of 7 active joints; shoulder-3 DOF, elbow-1 DOF, forearm-1 DOF, and wrist -2 DOF. Also extra passive joints are required in exoskeleton design to compensate for joint misalignments. A few cable driven exoskeletons have been developed to achieve the muscle-tendon like behaviour. However, a large number of actuators are required in the cable-driven system that makes it a complex and bulky system. Joints such as shoulder and wrist have multiple DOF roughly originating from a single point. Such joints are difficult to imitate using electric motors since several actuators need to be placed in a confined area. Also the axis of rotation of all the actuators should pass through a single point similar to the anatomical joint having multiple DOF and the distance between centres of rotations should be as small as possible to make an efficient joint. To match this parallel manipulators have been proposed for such applications however they have limited stiffness and dexterity. A solution for substituting multiple DOF using a single actuator is possible by modelling like spherical magnet arrays using the magnetic charge [109], 3D positions in the spherical or ball socket joint can be accessed by creating a magnetic field on the surface of a sphere. Although this concept is still in research, it may replace the use of multiple actuators for multiple DOF joint. ShouldeRO [37] is an alignment-free two DOF rehabilitation robot for the shoulder complex of the exoskeleton and a modular approach supported by Bowden cable has been proposed to provide motion in a 3D space without any restrictions.

\subsection{BANDWIDTH}

Control bandwidth of the actuator used in an exoskeleton defines the quality of rehabilitation services provided by it. Better performances can be achieved if the bandwidth of exoskeleton is same or higher than that of the patient. It can be obtained by increasing the frequency of the signal 
provided by the exoskeleton. A human operator has the frequency in the range of $1-2 \mathrm{~Hz}$ for unpredicted signal, 2-5 Hz for repetitive signal and $5 \mathrm{~Hz}$ for learned actions [30].

Each type of actuator has its own specification, however, the extra mechanism including gears and spring affects their bandwidth significantly. DC motors generally have a control bandwidth in the range up to $200 \mathrm{~Hz}$ [110], using a gear reduction technique, the bandwidth is reduced to $50 \mathrm{~Hz}$. The cable driven mechanism can reduce the same bandwidth up to $40 \mathrm{~Hz}$. DC motor connected with a spring can produce a lower bandwidth compared to the stand-alone DC motor depending on the stiffness of the spring. Pneumatic artificial muscles have a bandwidth of $2.4 \mathrm{~Hz}$, it is similar to the bandwidth of human muscles of $2.2 \mathrm{~Hz}$ [111]. On the other hand, open-loop hydraulic disk brake has a bandwidth of $10 \mathrm{~Hz}$ [112] and hydroelastic actuator with a spring can produce bandwidth in the range of 6.5-7.2 $\mathrm{Hz}[12]$.

\subsection{ENERGY CONSUMPTION}

The portability of a device cannot be achieved by only defining the mechanical construction of its actuator. Energy efficiency is also an important property for creating a portable system. Constant energy supply is needed to maintain the required joint torque. Human joints such as shoulder, elbow, and wrist do not require the same torque and it depends on the inertia and configuration of the arm, however, in exoskeletons a proper gravity compensation techniques may help in reducing the torque level; thus to consume less energy. Passive exoskeletons use the potential energy of springs for actuator either for providing assistive torque or compliance to the joint. These systems are torque balanced at the equilibrium position which effectively exhibits zero potential energy. WREX [85] and Armon [84] follow this concept. As passive exoskeletons do not require any energy source to keep the arm in a statically balanced condition, these concepts might be useful in developing a portable system but it can't provide active actuation force to the joint. Therefore, a hybrid system with optimal combination of active and passive rehabilitation system should be considered for portable exoskeleton design. It should also include two phases of passive rehabilitation; one with the supporting force and another with resistive force.

\section{DiscuSSION AND CONCLUSION}

A survey of the trials performed on the post-stroke patients [113] shows that the exoskeleton based rehabilitation does not provide any better rehabilitation compared to the manual therapy. The only advantage of using exoskeleton is that it can provide intense rehabilitation with repetitive training without fatigue of the therapist [11]. Also it can create different types of exercises needed for the rehabilitation of post-stroke patients and can make the therapy entertaining using different programmable game therapy [114]. The cost of human labour increases whereas the cost of technology reduces which in turn will make these exoskeletons less expensive in the future. The requirements of an exoskeleton are significantly different for two stakeholder groups [23]. Therapists would like an exoskeleton with innovative qualities which can produce medical advantages in terms of recovery. From their point of view, the actuation system of exoskeleton should be capable of producing a variety of exercises. However, the users' viewpoint is more of a personalised device, wearable and easy to use with customised and aesthetic look. Therefore, it is important to integrate the viewpoints of both stakeholders in the advancement of exoskeletons. Safety is being treated as one of the key criteria [23] for designing any human-based systems which can be achieved using specific mechanisms like the back-drivable system, complaint mechanism and serial elastic actuators [11]. The structure of the exoskeleton should follow the ISO 9000 norms [115] where the design should be safe from hardware approach and maintained electromechanically using different limit 
switch and mechanical constraints together with software control to keep the joint movement under anatomical limits. Also for rehabilitation, the training properties (list of exercise modules and rate of recovery), the structural properties (mechanical system, weight, size, the specification of equipment and control outlines) and the functional properties (cost, comfort, safety and ease of control) are considered to be the key design features. Incorporating all these features would make the exoskeleton innovative, interesting and task-oriented [116].

This paper mainly deals with the actuator and actuation system to develop a portable and costeffective upper arm exoskeleton, however, the ultimate aim of this work is to support stroke rehabilitation for enhancing patients experience by increasing their participation in the exercises. That way the mechanism of an exoskeleton should provide a fraction of the force required for any joint movements and rest should come from the patients. The design should incorporate the assistive force provided by the exoskeleton which is decreased with time as the patients gain more strength and later the force should be increased to generate more resistive force to improve the muscle strength. Therefore, the exercises produced by an exoskeleton should be adaptive over time to get the best recovery rate. The arm movement constitutes two components: gross manipulation and fine manipulation [76]. Shoulder and elbow joint are responsible for manipulating the arm in a larger 3D space as compared to the wrist joints which only provide small articulation for fine manipulation. The weight lifting and other strenuous activities are taken care of by shoulder and elbow joints whereas grasping, touching and other small-scale activities are performed by the wrist joint. Hence the design consideration of these joints is significantly different, in case of shoulder and elbow joint, the joint torque and degree of freedom are the main criteria therefore different actuation systems are implemented to reduce the size and weight of the system (includes the upper and lower arm). On the other hand, wrist and hand exoskeletons require fine control for object manipulation with maximum degree of freedom. In general, any actuation system for arm or hand should incorporate all types of rehabilitation exercises required for post-stroke patients.

From this overview, it is apparent that rehabilitation training of arm supported by exoskeletons can be achieved either by hardware or by software control. Though hardware approach requires a more complex mechanism, it is good for human-machine interactions due to the safety reasons. In software solution, patients may experience undesirable responses and sudden impact forces due to spurious signals or controller malfunctioning. On the other hand, hardware-based (passive) actuation can also work under no power condition or during sudden power cut. After the thorough literature search, it was concluded that a design should consist of eight distinct properties to make it a costeffective portable exoskeleton which can provide all types of rehabilitation including active, passive and stiffness control. These are:

1. To develop an innovative mechanism which is capable of enhancing torque to weight ratio compared with existing models, thus making use of smaller motors dealing with higher torques.

2. To combine both active and passive system in a single platform for adopting a standard rehabilitation therapy from acute to the final stages of rehabilitation for a better recovery rate.

3. To develop a passive rehabilitation system combined with an active gravity compensating mechanism which is adaptable to different loading conditions during exercises.

4. To introduce joint stiffness changing mechanism into the system that allows more resistive force to have different levels of difficulty during therapy.

5. These features should provide standard rehabilitation therapy without deviating from the main objective of making it lightweight, user-friendly and a wearable device. 
6. To make the system light and energy efficient utilising smart materials and mechanisms for carrying out different rehabilitation exercises, this property supports portability of the overall design.

7. To make the system affordable for stroke patients offering the benefits of stand-alone 'take home' exoskeletons.

8. The system should not compromise with the safety features at any point, therefore, the system should restrict the joint motion beyond the anatomical limits using mechanical stop or limit switches.

\section{Conflicts of Interest: None}

Funding: None

Ethical Approval: Not required

\section{REFERENCES}

[1] Stroke Association UK, State of the Nation: stroke statistics, https:/www.stroke.org.uk/resources/state-nation-strokestatistics; 2017 [accessed: Jan- 2017].

[2] Legg L, Drummond A, Langhorne P. Occupational therapy for patients with problems in activities of daily living after stroke. The Cochrane Library. 2006.

[3] ReNeuron Group plc. CTX cells for Stroke Disability, http://www.reneuron.com/products/ctx-cells-for-strokedisability/; 2017 [accessed: April - 2017].

[4] Clarke DJ, Tyson S, Rodgers H, Drummond A, Palmer R, Prescott M, et al. Why do patients with stroke not receive the recommended amount of active therapy (ReAcT)? Study protocol for a multisite case study investigation. BMJ Open. 2015;5:e008443.

[5] Norouzi-Gheidari N, Archambault PS, Fung J. Effects of robot-assisted therapy on stroke rehabilitation in upper limbs: systematic review and meta-analysis of the literature. Journal of Rehabilitation Research and Development. 2012;49:479.

[6] Rahman MH, Rahman MJ, Cristobal O, Saad M, Kenné J-P, Archambault PS. Development of a whole arm wearable robotic exoskeleton for rehabilitation and to assist upper limb movements. Robotica. 2015;33:19-39.

[7] Cannan J, Hu H. Upper body rehabilitation: a survey. Colchester CO4 3SQ, UK. 2012.

[8] Pons JL. Wearable robots: biomechatronic exoskeletons: John Wiley \& Sons; 2008.

[9] Nef T, Guidali M, Riener R. ARMin III-arm therapy exoskeleton with an ergonomic shoulder actuation. Applied Bionics and Biomechanics. 2009;6:127-42.

[10] Beattie E, McGill N, Parrotta N, Vladimirov N. Titan: A Powered, Upper-Body Exoskeleton. Retrieved November. 2012;22:2014.

[11] Maciejasz P, Eschweiler J, Gerlach-Hahn K, Jansen-Troy A, Leonhardt S. A survey on robotic devices for upper limb rehabilitation. Journal of Neuroengineering and Rehabilitation. 2014;11:3.

[12] Vitiello N, Lenzi T, Roccella S, De Rossi SMM, Cattin E, Giovacchini F, et al. NEUROExos: A powered elbow exoskeleton for physical rehabilitation. IEEE Transactions on Robotics. 2013;29:220-35.

[13] Stienen AH, Hekman EE, Prange GB, Jannink MJ, Aalsma AM, van der Helm FC, et al. Dampace: Design of an exoskeleton for force-coordination training in upper-extremity rehabilitation. Journal of Medical Devices. 2009;3:031003.

[14] Otten A, Voort C, Stienen A, Aarts R, van Asseldonk E, van der Kooij H. LIMPACT: A hydraulically powered selfaligning upper limb exoskeleton. IEEE/ASME Transactions on Mechatronics. 2015;20:2285-98.

[15] Pylatiuk C, Kargov A, Gaiser I, Werner T, Schulz S, Bretthauer G. Design of a flexible fluidic actuation system for a hybrid elbow orthosis. IEEE International Conference on Rehabilitation Robotics: IEEE; 2009. p. 167-71.

[16] Klein J, Spencer S, Allington J, Bobrow JE, Reinkensmeyer DJ. Optimization of a parallel shoulder mechanism to achieve a high-force, low-mass, robotic-arm exoskeleton. IEEE Transactions on Robotics. 2010;26:710-5.

[17] Reinkensmeyer DJ, Wolbrecht ET, Chan V, Chou C, Cramer SC, Bobrow JE. Comparison of 3D, assist-as-needed robotic arm/hand movement training provided with Pneu-WREX to conventional table top therapy following chronic stroke. American Journal of Physical Medicine \& Rehabilitation/Association of Academic Physiatrists. 2012;91:S232. [18] Balasubramanian S, Wei R, Perez M, Shepard B, Koeneman E, Koeneman J, et al. RUPERT: An exoskeleton robot for assisting rehabilitation of arm functions. Virtual Rehabilitation, 2008: IEEE; 2008. p. 163-7.

[19] Culmer P, Jackson A, Makower S, Cozens J, Levesley M, Mon-Williams M, et al. A novel robotic system for quantifying arm kinematics and kinetics: Description and evaluation in therapist-assisted passive arm movements poststroke. Journal of Neuroscience Methods. 2011;197:259-69. 
[20] Marcheschi S, Salsedo F, Fontana M, Bergamasco M. Body extender: whole body exoskeleton for human power augmentation. IEEE International Conference on Robotics and Automation: IEEE; 2011. p. 611-6.

[21] Tondu B, Lopez P. Modeling and control of McKibben artificial muscle robot actuators. IEEE Control Systems. 2000;20:15-38.

[22] Landkammer S, Hornfeck R. A novel bio-inspired fluidic actuator for robotic applications. International Conference for Adaptive Structures and Technologies, The Hague2014.

[23] Wolff J, Parker C, Borisoff J, Mortenson WB, Mattie J. A survey of stakeholder perspectives on exoskeleton technology. Journal of Neuroengineering and Rehabilitation. 2014;11:169.

[24] Yu L, Wang J-p, Fang Q, Wang Y. Brunnstrom stage automatic evaluation for stroke patients using extreme learning machine. Biomedical Circuits and Systems Conference: IEEE; 2012. p. 380-3.

[25] Manna SK, Dubey, V.N. Upper arm exoskeleton - what specifications will meet users’ acceptability? . In: Fisher DG, editor. Robotics: New Research Nova Science Publisher; 2016. p. 123-69.

[26] Letier P, Avraam M, Horodinca M, Schiele A, Preumont A. Survey of actuation technologies for body-grounded exoskeletons. Proc Eurohaptics 2006 Conference: Citeseer; 2006. p. 497-500.

[27] Oda K, Isozumi S, Ohyama Y, Tamida K, Kikuchi T, Furusho J. Development of isokinetic and iso-contractile exercise machine "MEM-MRB” using MR brake. IEEE International Conference on Rehabilitation Robotics: IEEE; 2009. p. 6-11.

[28] Van Ham R, Sugar TG, Vanderborght B, Hollander KW, Lefeber D. Compliant actuator designs. IEEE Robotics \& Automation Magazine. 2009;16.

[29] Gupta A, O'Malley MK, Patoglu V, Burgar C. Design, control and performance of RiceWrist: a force feedback wrist exoskeleton for rehabilitation and training. The International Journal of Robotics Research. 2008;27:233-51.

[30] Brooks TL. Telerobotic response requirements. IEEE International Conference on Systems, Man and Cybernetics: IEEE; 1990. p. 113-20.

[31] Van Ninhuijs B, van der Heide L, Jansen J, Gysen B, van der Pijl D, Lomonova E. Overview of actuated arm support systems and their applications. Actuators: Multidisciplinary Digital Publishing Institute; 2013. p. 86-110.

[32] Ghozzi S, Jelassi K, Roboam X. Energy optimization of induction motor drives. IEEE International Conference on Industrial Technology: IEEE; 2004. p. 602-10.

[33] Rahman MS, Avi MTR. Exoskeleton Arm: the first step of real life iron suit. 2015.

[34] Agrawal SK, Dubey VN, Gangloff JJ, Brackbill E, Mao Y, Sangwan V. Design and optimization of a cable driven upper arm exoskeleton. Journal of Medical Devices. 2009;3:031004.

[35] Ching M, Wang DW. A five-bar-linkage force reflecting interface for a virtual reality system. IEEE International Conference on Robotics and Automation: IEEE; 1997. p. 3012-7.

[36] Ball SJ, Brown IE, Scott SH. MEDARM: a rehabilitation robot with 5DOF at the shoulder complex. IEEE/ASME International Conference on Advanced intelligent mechatronics: IEEE; 2007. p. 1-6.

[37] Dehez B, Sapin J. ShouldeRO, an alignment-free two-DOF rehabilitation robot for the shoulder complex. IEEE International Conference on Rehabilitation Robotics: IEEE; 2011. p. 1-8.

[38] Perry JC, Rosen J, Burns S. Upper-limb powered exoskeleton design. IEEE/ASME Transactions on Mechatronics. 2007;12:408-17.

[39] Dubey VN, Agrawal S. Study of an upper arm exoskeleton for gravity balancing and minimization of transmitted forces. Proceedings of the Institution of Mechanical Engineers, Part H: Journal of Engineering in Medicine. 2011;225:1025-35.

[40] Crea S, Cempini M, Moisè M, Baldoni A, Trigili E, Marconi D, et al. A novel shoulder-elbow exoskeleton with series elastic actuators. 6th IEEE International Conference on Biomedical Robotics and Biomechatronics: IEEE; 2016. p. 1248-53.

[41] Ragonesi D, Agrawal S, Sample W, Rahman T. Series elastic actuator control of a powered exoskeleton. Annual International Conference of the IEEE on Engineering in Medicine and Biology Society: IEEE; 2011. p. 3515-8.

[42] Chen Y, Fan J, Zhu Y, Zhao J, Cai H. A passively safe cable driven upper limb rehabilitation exoskeleton. Technology and Health Care. 2015;23:S197-S202.

[43] Taghirad H, Belanger P. Modeling and parameter identification of harmonic drive systems. Transactions-American Society of Mechanical Engineers Journal of Dynamic Systems Measurement and Control. 1998;120:439-44.

[44] Kawamoto H, Sankai Y. Power assist system HAL-3 for gait disorder person. Computers helping people with special needs. 2002:19-29.

[45] Letier P, Avraam M, Veillerette S, Horodinca M, De Bartolomei M, Schiele A, et al. SAM: A 7-DOF portable arm exoskeleton with local joint control. IEEE/RSJ International Conference on Intelligent Robots and Systems: IEEE; 2008. p. 3501-6.

[46] Carignan C, Liszka M. Design of an arm exoskeleton with scapula motion for shoulder rehabilitation. 12th International Conference on Advanced Robotics: IEEE; 2005. p. 524-31.

[47] Diller S, Majidi C, Collins SH. A lightweight, low-power electroadhesive clutch and spring for exoskeleton actuation. IEEE International Conference on Robotics and Automation: IEEE; 2016. p. 682-9.

[48] Brown M, Tsagarakis N, Caldwell D. Exoskeletons for human force augmentation. Industrial Robot: An International Journal. 2003;30:592-602. 
[49] Stienen AH, Hekman EE, Ter Braak H, Aalsma AM, van der Helm FC, van der Kooij H. Design of a rotational hydro-elastic actuator for an active upper-extremity rehabilitation exoskeleton. 2nd IEEE RAS \& EMBS International Conference on Biomedical Robotics and Biomechatronics: IEEE; 2008. p. 881-8.

[50] Sasaki D, Noritsugu T, Takaiwa M. Development of active support splint driven by pneumatic soft actuator (ASSIST). IEEE International Conference on Robotics and Automation: IEEE; 2005. p. 520-5.

[51] Tsagarakis NG, Caldwell DG. Development and control of a 'soft-actuated'exoskeleton for use in physiotherapy and training. Autonomous Robots. 2003;15:21-33.

[52] O'Neill CT, Phipps NS, Cappello L, Paganoni S, Walsh CJ. A soft wearable robot for the shoulder: Design, characterization, and preliminary testing. International Conference on Rehabilitation Robotics: IEEE; 2017. p. 1672-8.

[53] Yang HD. Modeling and Analysis of a Novel Pneumatic Artificial Muscle and Pneumatic Arm Exoskeleton: Virginia Tech; 2017.

[54] Yap HK, Lim JH, Nasrallah F, Goh JC, Yeow RC. A soft exoskeleton for hand assistive and rehabilitation application using pneumatic actuators with variable stiffness. IEEE International Conference on Robotics and Automation: IEEE; 2015. p. 4967-72.

[55] Rai K. Design of soft actuator based hand-exoskeleton for rehabilitation and activities of daily living. 2018.

[56] Bar-Cohen Y. Current and future developments in artificial muscles using electroactive polymers. Expert Review of Medical Devices. 2005;2:731-40.

[57] Choi B, Choi HR. SKK hand master-hand exoskeleton driven by ultrasonic motors. IEEE/RSJ International Conference on Intelligent Robots and Systems: IEEE; 2000. p. 1131-6.

[58] Petit L, Gonnard P. Industrial design of a centimetric "TWILA" ultrasonic motor. Sensors and Actuators A: Physical. 2005;120:211-24.

[59] Heo P, Gu GM, Lee S-j, Rhee K, Kim J. Current hand exoskeleton technologies for rehabilitation and assistive engineering. International Journal of Precision Engineering and Manufacturing. 2012;13:807-24.

[60] Dittmer DK, Buchal RO, MacArthur DE. The SMART Wrist-Hand Orthosis (WHO) for Quadriplegic Patients. JPO: Journal of Prosthetics and Orthotics. 1993;5:73.

[61] Tang T, Zhang D, Xie T, Zhu X. An exoskeleton system for hand rehabilitation driven by shape memory alloy. IEEE International Conference on Robotics and Biomimetics: IEEE; 2013. p. 756-61.

[62] Copaci D, Cano E, Moreno L, Blanco D. New Design of a Soft Robotics Wearable Elbow Exoskeleton Based on Shape Memory Alloy Wire Actuators. Applied Bionics and Biomechanics. 2017;2017.

[63] Hope J, McDaid A. Development of Wearable Wrist and Forearm Exoskeleton with Shape Memory Alloy Actuators. Journal of Intelligent \& Robotic Systems. 2017;86:397-417.

[64] Carignan C, Tang J, Roderick S, Naylor M. A configuration-space approach to controlling a rehabilitation arm exoskeleton. 10th International Conference on Rehabilitation Robotics: IEEE; 2007. p. 179-87.

[65] Rahman M, Ouimet T, Saad M, Kenne J, Archambault P. Development and control of a wearable robot for rehabilitation of elbow and shoulder joint movements. 36th Annual Conference on IEEE Industrial Electronics Society: IEEE; 2010. p. 1506-11.

[66] Jang M, Dawson F, Bailak G. Control system for multiple joint robotic arm powered by ultrasonic motor. Nineteenth Annual IEEE Applied Power Electronics Conference and Exposition: IEEE; 2004. p. 1844-8.

[67] Brackbill EA, Mao Y, Agrawal SK, Annapragada M, Dubey VN. Dynamics and control of a 4-dof wearable cabledriven upper arm exoskeleton. IEEE International Conference on Robotics and Automation: IEEE; 2009. p. $2300-5$.

[68] Ren Y, Park H-S, Zhang L-Q. Developing a whole-arm exoskeleton robot with hand opening and closing mechanism for upper limb stroke rehabilitation. IEEE International Conference on Rehabilitation Robotics: IEEE; 2009. p. 761-5.

[69] Gopura RARC, Kiguchi K, Li Y. SUEFUL-7: A 7DOF upper-limb exoskeleton robot with muscle-model-oriented EMG-based control. IEEE/RSJ International Conference on Intelligent Robots and Systems: IEEE; 2009. p. $1126-31$.

[70] Rocon E, Belda-Lois J, Ruiz A, Manto M, Moreno JC, Pons J. Design and validation of a rehabilitation robotic exoskeleton for tremor assessment and suppression. IEEE Transactions on Neural Systems and Rehabilitation Engineering. 2007;15:367-78.

[71] French JA, Rose CG, O’malley MK. System characterization of MAHI Exo-II: a robotic exoskeleton for upper extremity rehabilitation. ASME 2014 Dynamic Systems and Control Conference: American Society of Mechanical Engineers; 2014. p. V003T43A6-VT43A6.

[72] Vertechy R, Frisoli A, Dettori A, Solazzi M, Bergamasco M. Development of a new exoskeleton for upper limb rehabilitation. IEEE International Conference on Rehabilitation Robotics: IEEE; 2009. p. 188-93.

[73] Colizzi L, Lidonnici A, Pignolo L. The aramis project: a concept robot and technical design. Journal of Rehabilitation Medicine. 2009;41:1011-5.

[74] Frisoli A, Procopio C, Chisari C, Creatini I, Bonfiglio L, Bergamasco M, et al. Positive effects of robotic exoskeleton training of upper limb reaching movements after stroke. Journal of Neuroengineering and Rehabilitation. 2012;9:36.

[75] Johnson G, Carus D, Parrini G, Marchese S, Valeggi R. The design of a five-degree-of-freedom powered orthosis for the upper limb. Proceedings of the Institution of Mechanical Engineers, Part H: Journal of Engineering in Medicine. 2001;215:275-84.

[76] Manna SK, Bhaumik S. A bioinspired 10 DOF wearable powered arm exoskeleton for rehabilitation. Journal of Robotics. 2013;2013. 
[77] Pirondini E, Coscia M, Marcheschi S, Roas G, Salsedo F, Frisoli A, et al. Evaluation of the effects of the Arm Light Exoskeleton on movement execution and muscle activities: a pilot study on healthy subjects. Journal of Neuroengineering and Rehabilitation. 2016;13:9.

[78] Garrec P, Friconneau J, Measson Y, Perrot Y. ABLE, an innovative transparent exoskeleton for the upper-limb. IEEE/RSJ International Conference on Intelligent Robots and Systems: IEEE; 2008. p. 1483-8.

[79] Stein J, Narendran K, McBean J, Krebs K, Hughes R. Electromyography-controlled exoskeletal upper-limbpowered orthosis for exercise training after stroke. American Journal of Physical Medicine \& Rehabilitation. 2007;86:255-61.

[80] Allington J, Spencer SJ, Klein J, Buell M, Reinkensmeyer DJ, Bobrow J. Supinator extender (SUE): a pneumatically actuated robot for forearm/wrist rehabilitation after stroke. Annual International Conference of the IEEE on Engineering in Medicine and Biology Society: IEEE; 2011. p. 1579-82.

[81] Beekhuis JH, Westerveld AJ, van der Kooij H, Stienen AH. Design of a self-aligning 3-DOF actuated exoskeleton for diagnosis and training of wrist and forearm after stroke. IEEE International Conference on Rehabilitation Robotics: IEEE; 2013. p. 1-5.

[82] White GC, Xu Y. An active vertical-direction gravity compensation system. IEEE Transactions on Instrumentation and Measurement. 1994;43:786-92.

[83] Wu T-M, Chen D-Z. Biomechanical study of upper-limb exoskeleton for resistance training with three-dimensional motion analysis system. Journal of Rehabilitation Research \& Development. 2014;51:111-26.

[84] Herder JL, Vrijlandt N, Antonides T, Cloosterman M, Mastenbroek PL. Principle and design of a mobile arm support for people with muscular weakness. Journal of Rehabilitation Research and Development. 2006;43:591.

[85] Housman SJ, Le V, Rahman T, Sanchez RJ, Reinkensmeyer DJ. Arm-training with T-WREX after chronic stroke: preliminary results of a randomized controlled trial. 10th International Conference on Rehabilitation Robotics: IEEE; 2007. p. 562-8.

[86] Hollander KW, Sugar TG, Herring DE. Adjustable robotic tendon using a'Jack Spring'/spl trade. 9th International Conference on Rehabilitation Robotics, 2005 icorr 2005: IEEE; 2005. p. 113-8.

[87] Kramer G, Romer GR, Stuyt HJ. Design of a Dynamic Arm Support (D AS) for gravity compensation. 10th International Conference on Rehabilitation Robotics: IEEE; 2007. p. 1042-8.

[88] Sanchez R, Reinkensmeyer D, Shah P, Liu J, Rao S, Smith R, et al. Monitoring functional arm movement for homebased therapy after stroke. 26th Annual International Conference of the IEEE on Engineering in Medicine and Biology Society: IEEE; 2004. p. 4787-90.

[89] Cannella G. Design and analysis of a gravity balanced low-cost hybrid arm support for stroke rehabilitation: University of Southampton; 2015.

[90] Kircanski NM, Goldenberg AA. An experimental study of nonlinear stiffness, hysteresis, and friction effects in robot joints with harmonic drives and torque sensors. The International Journal of Robotics Research. 1997;16:214-39.

[91] Vanderborght B, Albu-Schäffer A, Bicchi A, Burdet E, Caldwell DG, Carloni R, et al. Variable impedance actuators: A review. Robotics and Autonomous Systems. 2013;61:1601-14.

[92] Migliore SA, Brown EA, DeWeerth SP. Biologically inspired joint stiffness control. IEEE International Conference on Robotics and Automation: IEEE; 2005. p. 4508-13.

[93] Speich J. A Weil-Behaved Revolute Flexure Joint for Compliant Mechanism Design. Analysis. 1999;2:2.

[94] Pedrocchi A, Ferrante S, Ambrosini E, Gandolla M, Casellato C, Schauer T, et al. MUNDUS project: MUltimodal Neuroprosthesis for daily Upper limb Support. Journal of Neuroengineering and Rehabilitation. 2013;10:66.

[95] Loureiro RC, Belda-Lois JM, Lima ER, Pons JL, Sanchez-Lacuesta JJ, Harwin WS. Upper limb tremor suppression in ADL via an orthosis incorporating a controllable double viscous beam actuator. International Conference on Rehabilitation Robotics: IEEE; 2005. p. 119-22.

[96] Schiavi R, Grioli G, Sen S, Bicchi A. VSA-II: A novel prototype of variable stiffness actuator for safe and performing robots interacting with humans. IEEE International Conference on Robotics and Automation: IEEE; 2008. p. 2171-6.

[97] Jafari A, Tsagarakis NG, Caldwell DG. AwAS-II: A new actuator with adjustable stiffness based on the novel principle of adaptable pivot point and variable lever ratio. IEEE International Conference on Robotics and Automation: IEEE; 2011. p. 4638-43.

[98] Kim B-S, Song J-B. Hybrid dual actuator unit: A design of a variable stiffness actuator based on an adjustable moment arm mechanism. IEEE International Conference on Robotics and automation: IEEE; 2010. p. 1655-60.

[99] Tsagarakis NG, Sardellitti I, Caldwell DG. A new variable stiffness actuator (CompAct-VSA): Design and modelling. IEEE/RSJ International Conference on Intelligent Robots and Systems: IEEE; 2011. p. 378-83.

[100] Groothuis SS, Rusticelli G, Zucchelli A, Stramigioli S, Carloni R. The vsaUT-II: A novel rotational variable stiffness actuator. IEEE International Conference on Robotics and Automation: IEEE; 2012. p. 3355-60.

[101] Kim B-S, Song J-B. Design and control of a variable stiffness actuator based on adjustable moment arm. IEEE Transactions on Robotics. 2012;28:1145-51.

[102] Catalano MG, Grioli G, Garabini M, Bonomo F, Mancini M, Tsagarakis N, et al. Vsa-cubebot: A modular variable stiffness platform for multiple degrees of freedom robots. IEEE International Conference on Robotics and Automation: IEEE; 2011. p. 5090-5.

[103] Nam K-H, Kim B-S, Song J-B. Compliant actuation of parallel-type variable stiffness actuator based on antagonistic actuation. Journal of Mechanical Science and Technology. 2010;24:2315-21. 
[104] Choi J, Hong S, Lee W, Kang S, Kim M. A robot joint with variable stiffness using leaf springs. IEEE Transactions on Robotics. 2011;27:229-38.

[105] Wolf S, Eiberger O, Hirzinger G. The DLR FSJ: Energy based design of a variable stiffness joint. IEEE International Conference on Robotics and Automation: IEEE; 2011. p. 5082-9.

[106] Fumagalli M, Barrett E, Stramigioli S, Carloni R. The mVSA-UT: A miniaturized differential mechanism for a continuous rotational variable stiffness actuator. 4th IEEE RAS \& EMBS International Conference on Biomedical Robotics and Biomechatronics: IEEE; 2012. p. 1943-8.

[107] Huang T-H, Kuan J-Y, Huang H-P. Design of a new variable stiffness actuator and application for assistive exercise control. IEEE/RSJ International Conference on Intelligent Robots and Systems: IEEE; 2011. p. 372-7.

[108] Van Ham R, Vanderborght B, Van Damme M, Verrelst B, Lefeber D. MACCEPA, the mechanically adjustable compliance and controllable equilibrium position actuator: Design and implementation in a biped robot. Robotics and Autonomous Systems. 2007;55:761-8.

[109] Motoasca T, Gysen B, Lomonova E. Modeling of spherical magnet arrays using the magnetic charge model. IEEE Transactions on Magnetics. 2013;49:4109-12.

[110] Schiele A, Hirzinger G. A new generation of ergonomic exoskeletons-the high-performance x-arm-2 for space robotics telepresence. IEEE/RSJ International Conference on Intelligent Robots and Systems: IEEE; 2011. p. 2158-65.

[111] Aaron S, Stein R. Comparison of an EMG-controlled prosthesis and the normal human biceps brachii muscle. American Journal of Physical Medicine \& Rehabilitation. 1976;55:1-14.

[112] Stienen AH, Hekman EE, Schouten AC, van der Helm FC, van der Kooij H. Suitability of hydraulic disk brakes for passive actuation of upper-extremity rehabilitation exoskeleton. Applied Bionics and Biomechanics. 2009;6:103-14.

[113] Lo AC, Guarino PD, Richards LG, Haselkorn JK, Wittenberg GF, Federman DG, et al. Robot-assisted therapy for long-term upper-limb impairment after stroke. New England Journal of Medicine. 2010;362:1772-83.

[114] Reinkensmeyer DJ, Boninger ML. Technologies and combination therapies for enhancing movement training for people with a disability. Journal of Neuroengineering and Rehabilitation. 2012;9:17.

[115] Duchemin G, Poignet P, Dombre E, Peirrot F. Medically safe and sound [human-friendly robot dependability]. IEEE Robotics \& Automation Magazine. 2004;11:46-55.

[116] Ju M-S, Lin C-C, Chen S-M, Hwang I-S, Kung P-C, Wu Z-W. Applications of Robotics to Assessment and Physical Therapy of Upper Limbs of Stroke Patients. Rehabilitation Robotics: InTech; 2007 